\title{
Handcrafted and Vegetable Dyed Products of India: History, Genesis and Contemporary Approach
}

\begin{abstract}
Ms. Shruti Tomar
Ph.D.Scholar, Department of Clothing and Textiles, The M.S. University of Baroda, Vadodara Trainee- Textile Design, Design Teacher's Development Programme, National Institute of Design, Ahmedabad

\section{Dr. Madhu Sharan}

Associate Professor, Department of Clothing and Textiles The M.S. University of Baroda, Vadodara

Abstract: The present paper illustrates the sumptuousness and importance of traditional rural textile industry in India and at the same time, the plight of the producers engaged in it. The art of fabric production, its decoration and coloring are deeply embedded in the Indian culture and it has enjoyed royal and aristocratic patronage during pre-independence days. Consequent, industrialization marked the steady decline in crafts market and finally livelihood potential for the artisan. The traditional knowledge of art still persists in some of the rural pockets and also, there do exist emerging demands of natural and organic products. But with the prevalence of fragmented value chain, there is a predominance of confusion between the maker and the end user. Hence, the paper has been chalked out with a view to making reference to the inception of time-honored specified crafts in India and their co-existence with mechanized tools, equipment and products along with a need and solutions to propel their survival further.
\end{abstract}

Key words: Traditional crafts, natural dyes, sustainability, survival, eco-friendliness

\section{INTRODUCTION:}

'Today, an argument, an attitude faces crafts and artisans in India. This is the argument of economics, of sustainability, of marketability, which is the argument of financial survival...(But) those who believe that crafts are only about beauty and aesthetics are in error, just as those who believe in the other argument, the economic argument, and think that paying for itself is the sole justification, are wrong...

The hard argument, the real argument, which overrides all others, is not exclusively about sentiment or reason - but about common sense. And that common sense tells that whatever we do in terms of economic planning and development in India, there will always be several hundred million people in this country, the figure being unverified, who cannot but live with and through the work of their hands. Now it is a great compensation of nature that these hundreds and millions of people have talent in their hand, which the assembly-liners and the free-marketers do not quite concede. And that talent is the unexplored reservoir which needs to be used for their good which means the greater good of the great number of the people of India.' [..Gopalkrishna Gandhi]

Handicraft is the second largest source of employment in India, after agriculture. Yet India's hand industries are in a crisis of misunderstanding. Encouraging statistics of growth at the macro level often mask a tragic neglect at the micro level. The centrality of hand production to national wellbeing is not comprehended in most decision-making circles. There are neglect and ignorance of how artisanal production - such as the weaving of a sari or shawl or making the utterly simple kullhar (hand-thrown traditional mug of clay) for drinking tea - contains within itself the incredibly rich philosophy of India's civilization, its culture and its practices. These persistent misconceptions remain as hangovers of India's colonial experience. Because modernity has been primarily framed as an evolution or adoption of ideas and ways of living that mimic the West, the products of the artisan are branded as 'local', 'primitive', 'ethnic' and similar adjectives that can denote qualitatively inferior 
products when compared with machine-made, mass-produced objects of uniform quality. Official support schemes, developed from policies that were designed to transform India into modernity, therefore adopted the orientation that artisans were persons who belonged to a pre-industrial past. From this, an attitude could quickly follow that they were liabilities on a strained exchequer. Sustaining them was a burden dictated by the politics of poverty rather than the logic of efficiency implicit in modern day economic theory (Anony. 2011, Jaitley1990).

India's fabled wealth that attracted waves of conquerors, merchants, speculators and adventurers was built on what it produced. This was not agricultural commodities or raw materials, but the finest finished goods that fetched huge premiums in global markets. Imperialism converted the production and trade in Indian goods into the production of commodities and raw materials that could be converted in the metropolitan economy and then sold back to the colonial market (Edward 2011).

There is thus neglect and ignorance of the value of artisanal production, its scale and potential within rapidly changing markets, and its critical contribution to social and environmental stability. The case for the handicrafts sector rests on a conviction that despite enormous challenges the hand sector sits on the verge of an explosive growth due to a convergence of incremental inputs over the decades and new market opportunities. Rightly recognized and supported, the opportunity can provide the economy with key drivers of specialization and competence in global manufacturing and services, sustain and build employment for millions of citizens including those in remote rural locations, empower vast number of citizens still on the margin, reinforce educational efforts, and address major cultural issues and do all these is an environmentally sustainable manner (Jaitley 1990, Balram 2011).

Also, the discussion of the possibilities of reusing natural dyes is currently increasing. One of the causing factors of this discussion is the regulation that prohibits the usage of certain synthetic dyes, due to their chemical ingredients which may be harmful to human beings and the environment. The prohibited dyes, for example, are those containing the diazonium salt (such as naphthol, which is widely used in batik production), since the salt is a carcinogenic substance. The regulation brings about a considerable impact on the production sector, especially in the sector known as textile and textile products, and to the consumers of the synthetic dyes in general. Natural dyeing and printing units can not only provide a means of livelihood to the rural artisans but also can offer lots of exciting challenges in the ever changing fashion market by varying combinations of colors and designs. Thus, the present paper aims to focus on the strengths, socio-cultural significance and glorious past of Indian traditional crafts and dyeing technology (Narayan 2010).

\section{Crafts and its Practitioners in India: for the People, of the People and by THE PEOPLE}

Craft is both a method of industrial production and a form of an artistic activity. Before the introduction of machinery, every article of domestic use was produced by hand. If a craftsman did his job perfectly, he could easily acquire a patron who normally used to keep him in continuous employment. In a gradual extending world the craftsman became the keystone of a developing commerce. He organized guilds which absorbed his sons in his trade, for there is a strong tradition of continuity by inheritance in his history of craftsmanship. Particular techniques passed down in families for generations, and even apprenticeship was a quasi paternal relationship. Thus, the craftsman increased gradually in individuality, security, scope and importance until the invention of machinery revolutionized industrial production. From painstaking integration of strips of grass to fashion the first garment, to the intricate and extraordinary designs wrought by the intersperses of threads on a loom, the weaver of India has harmonized the ingenuity of his mind, hands and creative spirit to spread before the world the finest and most varied of textiles woven anywhere.

With the introduction of machinery there has been a lot of change in the traditional craftsmanship, even then a worker who produces an article by handwork is still a craftsman in spite of his labour being facilitated by an electric motor or by machine spun yarns; the status of craftsman may change as become part of a larger industrial policy, but despite these apparently inimical developments craft remains an essential method of production in many lines of manufacture. Since the real India still, consists of rural India where nearly 80 percent of its people live and work. India being an agricultural country, the people of rural India are essentially farmers engaged in producing food, artisans engage in producing artifacts and professionals providing services to farmers (Balram 2011, Saraf 1991). 
Hence, Indian craftsman is the organic element in the national life. Products of everyday life are used by and relate very closely to millions of ordinary people. Especially in the developing countries, the mundane products acquire greater significance because of the special nature of the economic, social and human problems existing there. Right from the type of caps worn, turbans adorned, draping style of dhoti, colors, fabrics, motifs to the footwear worn; everything spoke about its wearer as well as the maker. Dr. Forbes Watson, supports his observation of light textures being used by the fair sex and the thicker ones by the sterner sex with the following stanza from Urdu poem:

'Aate hain apne munh pe dupatte ko tan kar;

Dete hain ham ko sharbat-i-didar chhan kar.'

('She comes with veil pulled over her face;

She gives us to drink the charm of her eyes, all the purer for being filtered.')

Thus, handcrafted Indian textiles have steeped in tradition and are living heritage of the glory of India. Over the decades, these have witnessed the renaissance in the promotion and revival of techniques, some of which were in danger of becoming extinct.

\section{Organic Colours in Traditional india: Origin, Genesis and Cultural SIGNIFICANCE}

Jaitley $\mathbf{J}$. has rightly stated that there can be no explanation to the initial urge to add embellishment to cloth, than the desire to bring color, design, vivacity and an identity to something which is plain austere. The practice of painting cloth, palm leaf, leather and wood for ritual use as well as for leisure, finds frequent mention in the classical Sanskrit literature of India. It has always been renowned for the excellence and wide variety of her textiles, ranging from fine muslins to silk brocades and woolen shawls. These have been woven and embellished in many distinctive ways for centuries. The subtle use of color in Indian embroidered, painted and printed textiles, distinguished them from those produced elsewhere, and made these textiles very popular abroad.

Considering the great antiquity of India's dyeing skills, its expertise in printing cloth with dyes and pigments probably matured quite early. There is some evidence to indicate the presence of blockprinting technology as early as fifth century B.C. Although no printed material survives from this early period, references to colored and patterned clothes abound in literary texts. From the material evidence that has come down to us, the cotton fragments unearthed at sites such as Fustat and Quesiral-Qadim in Egypt appears to be the earliest known examples of printed Indian fabric, produced probably in Gujarat or the neighboring areas of western India. However, there are numerous references to dyes and dyed textiles in the classical literature of India. The Vedas, India's most revered scriptures, refer to the tinctorial properties of several dyestuffs used centuries ago. There are also references to dyes and their use in the celebrated Arthshastra of Kautilya. The cave paintings of Ajanta and elsewhere bear testimony to the use of printed and dyed costumes near 1400 years ago. The use of mordants was known in at least the second millennium B.C. The Indian craftsman's knowledge of the technology of mordants and its use in textiles remained a closely guarded secret for a long time and later slowly it started seeping out (Mohanty 1900, Edward 2012).

Narayanswamy S. adds, there has been so much said and written about the beauty and value of the old-fashioned dye-stuffs and dyeing processes and their superiority to the modern colouring matters, that many well-meaning people of artistic tastes have never ceased to deplore the discovery and introduction of the so-called aniline or coal dyes, and to regard them as a serious detriment to the art of dyeing. This important and highly specialized art of dyeing has not advanced during nearly two thousand years is, on the face of it absurd. A very little knowledge of dyestuffs forces recognition of the fact that many of the very best, fastest and the most beautiful of the dyes of people in those dayssuch as cochineal- an insect- with which they dyed practically all of their fast pinks and scarlets; logwood, with which silk as well as wool was, and is still dyed black; fustic(wood of an American tree) which was used for fast yellows on wool and cotton, was known to the world at large since seventeenth century (Narayan 2010).

References explain that the earliest dyes were probably of vegetable origin, discovered by accidentally staining garments with juices of fruits or plants. Fruits in common use- black berries, huckle berries, peaches and like- fruits of cactus-whose juice could be used if nothing better presented itself, to dye 
or stain light colored fabrics. At the times when vegetable dyes were discovered, in one part of the world, which in the hands of those who knew how to work with them, gave colors both fast and beautiful. And thus grew and developed the art of the professional dyer. In many widely separated countries, such as India, Java, south and Central America, plants are found, known as indigo feriae, who juices yellow when fresh turns blue when exposed to the air. So, little by little the knowledge of these natural dyestuffs and their application grew and expanded (Jahan and Mishra 2009, Narayan 2010).

The opening of trade to the Far East, due to the discovery of the sea route round the Cape of Good Hope, brought to Europe the free use of some of the Indian dyestuffs. Indigo, for instance, was introduced for the first time in considerable quantities and, after much opposition, completely took the place of the much inferior dyestuff. For yellow, the old saffron dye was superseded by the more powerful, but still rather fugitive, turmeric, or Indian saffron. The wood of the trees probably contains the same coloring matter. The color is not very easy to extract, but when used with mordants of chromium, aluminum or tin salts, it dyes wool various shades of red and reddish brown. The wellknown brown dyes known as cutch (catechu) and ganbier are the forms of dark colored pastes, formed by evaporating infusions of leaves, seed pods, nuts and sometimes the wood of various species of acacia and areca trees (Mohanty 1990, Narayan 2010).

However, with advances in chemistry in the 18th and 19th century and with the use of synthetic dyes derived from many substances, there was a gradual decline in the use of natural dyes which were more expensive and, in many ways, more difficult to use. Natural dyeing therefore, ceased in most of the places. In some of these places, synthetic dyes were used in combination of natural dyes. Later, in the beginning of 21st century, again this dyeing craft was revived, encouraged and re-investigated due to the increased concerns relevant to the pollution created by man-made cheaper, easily available and fast synthetic dyes.

Also, a great deal of importance has always been attached to color in India. India has always been exalted and remembered fondly as the country of colors. From the deep orange marigold flowers that bejewel almost every celebration to the deep hues of red that deck up the bride on her most important day, color in India has, over time, become synonymous with religion - an expression of faith and beliefs. In a country as diverse and culturally vibrant as India, it is perhaps the common, simple expressions of color that hold together the multitudes of outlooks, lifestyles, and traditions. The symbolism of color stands out and controls every aspect of life in India, be it religion, politics, festivals, or celebrations. In India, be it the north, south, west, or east, color and culture go hand in hand. Costumes and textiles are worn as per occasions and ceremonies. For eg; the pieces of safflower color worn as saris by women in swinging festival, and are referred to in this connection in the Baramasa Radhika:

"Sakhi, Sawan ki rit ai,

Shukhya hindole jhule;

Pehre kusum rang sari

Jhule Radhika pyari."

("Sawan (monsoon), dear, must have its due;

See Sukhya already on the swing;

Clad in the folds of safflower hue,

Behold the loved one of the ring,

Radha, merrily, merrily swing.")

\section{Tracing Persistence of Traditional and Rural Technology}

The Indian tradition is perhaps the only one in the world, which has one foot firmly planted in a time cycle going back by thousands of years. The traditional Indian artisans live in the villages in harmony with nature.

Results of the research carried out Sericulture and silk weaving of Assam, India revealed that the traditional dyeing is closely connected with handloom weaving and is an ancient art of the region. 
Dyeing with natural dyes was still in practice in some parts of Assam and vegetable dyeing of silk yarn was a usual practice. Vegetable dyes were obtained from various parts of plants and herbs such as stem, wood, root, bark, leaf, flower, fruits, and seeds, etc. the prominent among them are indigo, Isatis tinctoria, turmeric, Lawsonia inermis, Morinda, Madder, Elephant apple etc. (Chakravorty 2008).

A study conducted on traditional Karbis (tribe) knowledge of dye and dyeing techniques in Karbi Anglong District, Assam, India, highlighted that the use of dyes for imparting specific color or color combinations was found to play an important role in the social and religious life of the Karbis. Cotton (Gossypium herbaceum L.) and Eri silk were the traditional sources of yarn or fibers for weaving garments. Yarn, fibers, and garments were often reported to be dyed (e.g., black, blue, indigo, yellow, red, pink) with plant extracts, animals products, and even minerals. Dyes or colors were noted to carry important cultural value and therefore, uphold cultural identity. Traditional knowledge of herbal dyes and dyeing in this community as well was found to be facing threats from synthetic dyes and acculturation (Borthakur et al. 2012).

Another research on the uses of dye yielding plants by the local people in two famous handicrafts'Patchitra' in Pingla and 'Mat craft' in Sabang areas of Paschim Medinipur district, India, revealed that the indigenous knowledge of using the natural dye from plants was carried out from generation to generation without any transformation. An investigation done, recorded 15 dye yielding plants belonging to 11 families viz. Acacia catechu (L.f) Willd., Aegle marmelos (Linn.) Correa ex Roxb. Basella alba Linn., Bixa orellana Linn., Butea monosperma Taub., Clitoria ternatea Linn., Curcuma longa Linn., Enhydra fluctuans Lour., Erythrina suberosa Roxb., Lawsonia inermis Linn., Nyctanthes arbortristis Linn., Peristrophe tinctoria Nees. Tagetes erecta Linn., Tectona grandis Linn. f., Wedelia chinensis Merril, collected information about few plant species that were used largely in medicine by local vaid's and local ethnic people (Das P.K. et al 2012).

\section{WHAT NEEDS TO BE DONE?}

There is a great potential for the revival of the use of natural dyes in India to substitute synthetic colors in certain areas. In India, National Handloom Development Corporation is playing a leading role in the revival of the use of natural dyes. Promotion of natural dyes is expected to have a manifold effect including employment generation in the rural and tribal belt. The earning level of thousands of artisans and craftsmen can be raised if they trained and explained the importance of organic means of dyeing since there is a boom in the particular area. Despite all the traditional knowledge that India inhouses of articulating textiles and technology of coloring it with natural hues, there seem to be some loop-holes, that the crafts are still dying and the artisans are losing interest in their very own heritage. May be the planners should try to look from another end of the glass. The answer may lie in promoting and encouraging practitioners first to meet the market demands, rather than manipulating them as per the needs of the market.

Also, designers / aiders or activists planning solutions for the development of rural crafts, sustaining livelihoods or introducing eco-friendly concepts requires bearing following points in mind:

- There should be a very controlled balance between International openness and domestic protectivism. It is imperative for any foreign involvement to necessarily promote, not kill, local research and development talent.

- Every solution provided or suggested should suit local technology that is an availability of raw materials, manpower, skills, the volume of production, capital etc.

- Also, practitioners suitability needs to be understood like his preferences, geographic and social conditions, ergonomics etc.

- He should be made to realize ecological concerns relevant to natural dyes that are problems related to pollution, long term effects, etc in its means (processes) as well as in its ends (use). Only, if the artisan is educated regarding facts, then can he realize the importance of use of eco- friendly concepts.

- People and practitioners know their problems sometimes better than others. Planners and designers could learn a lot by a sincere study of people's own solutions (Balram 2011). 


\section{Conclusion}

The use of natural dyes has increased during the last couple of years, although, the usage of natural dyes as the substitute needs further careful research and consideration. This awareness is growing to the different side of the user's viz. designers, traditional art dyers, and printers, academic institute and researches museum etc. We know that synthetic dyes commonly used to dyeing of fabric but it is earlier found associated with environmental hazards, pollutants and having azo groups which provide the harmful effect the skin, lungs and respiratory system etc. At present European and American country has been stopped the use of synthetic dyes for the export market. Some of the village communities in India are still aware of vegetable dyeing. They are following the old traditional method for extraction of natural dyes, though, somewhere in combination of synthetic dyes. Also, it is also a sad fact many communities who were engaged in the traditional practices, are now shifting to other inferior professions. To promote the use and production of natural dyes it should be applied that more young artisans need to be encouraged and trained in dyeing activities in order to enhance market value of their handicrafts. Also, there is need to understand problems and prospects of practicing communities first and thereby developing solution strategies that could bring long-term benefits to them.

\section{REFERENCES}

[1] Aryan, S., (2005) Unknown masterpieces of folk and tribal art, New, Delhi: K.C. Aryan Home of Tribal Craft .

[2] Balram, S., (2011), Thinking design. New Delhi: Sage publication.

[3] Borthakur, T. R. (2012), 'Traditional knowledge of herbal dyes and cultural significance of colours amongst Karbis ethnic tribe in Northeast India', A Journal of Plants People and Applied Research , 10, pp. 593-604.

[4] Chattopadhyay, K.,(1963), Indian Handicrafts. New, Delhi: Allied Publisher.

[5] Chkarvorty R., Dutta P and Ghose K., (2008), 'Seri culture and traditional craft of silk weaving in Assam', Indian Journal of Traditional Knowledge , 9 (2), pp. 378-385.

[6] Craft Council of India (2011), 'Craft Economics and Impact Studies', http://councilofindia.org/ceis_final_report.pdf

[7] Das R. \& Shah D., (May 2011). 'Natural dye and its application'. Asian Textile Journal , 54-57.

[8] Das, A. and Mondal P., (2012), 'In Traditional Art Of 'Patchitra' In Pingla And Mat Crafts In Sabang Prospecting Proper Medicinal Value Inthe Paschim Medinipur District, Westbengal, India', International Journal of Life Sciences Biotechnology and Pharma Research , 1 (2), pp. 158-171.

[9] Edward, E., (2012), Textiles and Costumes of Gujarat. Ahmedabad: Mapin Publications.

[10] Jahan, A. and Mishra, S. (February 2009), 'Natural dyeing craft for handloom sector', Asian Dyer, pp. 50-54.

[11] Jaitley, J. ,(1990), The Crafts Tradition of India. London: Lustre Press.

[12] Mohanty B.C., Chandramouli K.V. and Naik H.D. ,(1900s), Natural Dyeing Processing of India. Ahmedabad: Calico Museum.

[13] Narayan, S., (January 2010). 'History of textiles and in particular entry of dyes', Colourage , 8084.

[14] Samanta P. \& Agrawal A.K, (December 2009), 'Application of Natural Dyes on Textiles', Indian Journal of Fibre and Textile Research , pp. 384-399.

[15] Saraf, D. (1991). In the Journey of Craft Development. New Delhi: Samparak.

[16] Tyabji, L. (2007). Threads and Voices. Marg publications.

[17] Varadarajan L., Patel K. (2008). Of Fibre and Loom- The Indian Tradition. Ahmedabad: National Institute of Design.

[18] Widiawati D. ,(2009), 'The Revival of the Usage of Natural Fibers and Natural Dyes in Indonesian Textile'. ITB Journal , Vol. 3 (No. 2), pp.115-128. 


\section{AUTHORS' BIOGRAPHY}

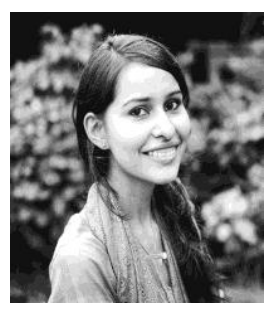

Ms. Shruti Tomar, is a Trainee- Textile Design under Design Teacher's Development Programme at National Institute of Design. She is pursuing Ph.D.at Dept. of Clothing and Textiles, The Maharaja Sayajirao University of Baroda. Her interest lies in Textile and Costume history, Craft Research and Documentation, Textile Design, Design Research and Design Process.

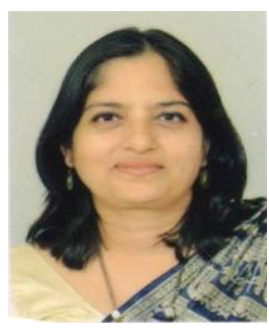

Dr. MadhuSharan, is an Associate Professor in the Department of Clothing and Textiles, The Maharaja Sayjirao University of Baroda, Vadodara. She has 28 years of Research and Teaching experience in the areas of Textile Dyes and Finishes, Sustainable Textiles and Clothing and Traditional Indian Textiles and Craft Studies. 